JHR

36,5

972

Received 10 July 2020 Revised 6 March 2021 2 May 2021

Accepted 24 May 2021

\section{Sleep quality, daytime sleepiness and daytime functioning among Thai obstructive sleep apnea patients receiving continuous positive airway pressure therapy}

\author{
Theerakorn Theerakittikul
}

\author{
Sleep Disorder Center, Center for Medical Excellence, Chiang Mai University, \\ Chiang Mai, Thailand and \\ Department of Internal Medicine, Faculty of Medicine, Chiang Mai University, \\ Chiang Mai, Thailand, and \\ Jindarat Chaiard and Jirawan Deeluea \\ Faculty of Nursing, Chiang Mai University, Chiang Mai, Thailand
}

\begin{abstract}
Purpose - The purpose is to assess the effectiveness of continuous positive airway pressure (CPAP) treatment
Abstract
Purpose - The purpose is to assess the effectiveness of continuous positive airway pressure (CPAP) treatment on sleep quality, daytime sleepiness and daytime functioning among Thai obstructive sleep apnea (OSA) patients.

Design/methodology/approach - A repeated measures clinical intervention design was implemented. Participants were 50 patients first time diagnosed with OSA and prescribed CPAP treatment. The intervention composed of CPAP health education, and follow-up evaluation. Data on CPAP adherence were downloaded from Smartcards of the CPAP device. The Thai PSQI, ESS and FSAQ-10 questionnaires were administered at baseline, 1-month, and 3-months. Descriptive statistics and repeated measure analysis with multilevel mixedeffects modeling approach were used.

Findings - Thirty-nine participants completed the study. Approximately 53\% $(n=25)$ and $71.1 \%(n=27)$ of the patients adhered to CPAP treatment by the end of the 1- and 3-months, respectively. After controlling for patients' adherence, at 1-month follow-up, the intervention improved quality of sleep $(\beta=-2.65,95 \% \mathrm{CI}=$ $-1.60,-4.13)$, daytime functioning $(\beta=3.24,95 \% \mathrm{CI}=1.87,4.61)$ and decreased daytime sleepiness $(\beta=-3.29,95 \% \mathrm{CI}=-1.85,-4.73)$. At 3 months, the intervention still improved quality of sleep $(\beta=-3.53$, $95 \% \mathrm{CI}=-2.05,-5.01)$, and daytime functioning $(\beta=4.34,95 \% \mathrm{CI}=2.76,5.92)$, and decreased daytime sleepiness $(\beta=-4.82,95 \% \mathrm{CI}=-3.16,-6.49)$.

Originality/value - Adherence to CPAP treatment is effective in improving sleep quality, daytime functioning and reducing daytime sleepiness. Patient-oriented strategies for enhancing CPAP adherence should be developed and implemented as a standard care in sleep clinics.
\end{abstract}

Keywords Sleep apnea, Sleep quality, Obstructive sleep apnea patients, Thailand

Paper type Research paper

(c) Theerakorn Theerakittikul, Jindarat Chaiard and Jirawan Deeluea. Published in Journal of Health Research. Published by Emerald Publishing Limited. This article is published under the Creative Commons Attribution (CC BY 4.0) licence. Anyone may reproduce, distribute, translate and create derivative works of this article (for both commercial and non-commercial purposes), subject to full attribution to the original publication and authors. The full terms of this licence may be seen at http:// creativecommons.org/licences/by/4.0/legalcode

This research was funded by a grant from Chiang Mai University. The authors would like to express their gratitude to patients at the Sleep Center, who participated in and contributed to this study.

Conflicts of interest: The authors declare no conflict of interest. 


\section{Introduction}

Obstructive sleep apnea (OSA) is a consequence of repeated obstruction of the upper airway due to relaxation of the pharyngeal and tongue muscles during sleep [1]. The prevalence of OSA around the world was 3\% to $38 \%$ [2, 3]. In Thailand, the prevalence of OSA based on an apnea-hypopnea index of 5 was $14 \%$ (15.4\% in men and $6.3 \%$ in women [4]). Health consequences of OSA range from daytime sleepiness, decreased productivity and increased risk of traffic accidents $[5,6]$.

While in the long-term OSA increases the risk of metabolic disorder, cardiovascular diseases, impaired cognition and premature mortality [7]. Management options for OSA ranging from lifestyle modifications, continuous positive airway pressure (CPAP), oral appliances and surgical interventions; however, CPAP therapy is the treatment of choice for OSA syndrome [8].

The positive effect of CPAP treatment results in improvements of those who adhere to regular CPAP use. Regular CPAP utilization has been reported to improve sleep quality and daily functioning and overall quality of life $[9,10]$. CPAP also improves objective sleep parameters, i.e. increasing NREM III or deep sleep stage [11]. Although CPAP is the goal standard treatment for OSA and has many health benefits, concerns about the low rate of adherence of OSA patients have been raised.

Extensive research on CPAP effectiveness and adherence to CPAP treatment has been reported; however, findings are not conclusive. Furthermore, information on CPAP adherence and its short- and long-term effectiveness in Thailand is limited. Our extensive literature search yielded only one publication addressing adherence to CPAP among Thai patients diagnosed with OSA [12], but researchers evaluated adherence to CPAP among a group of patients who had received CPAP treatment. The effectiveness of CPAP therapy was not evaluated in this study. In addition, OSA and its health consequences are not well recognized among the Thai population, and therefore, the seriousness of OSA most likely is underestimated. This lack or limited knowledge about OSA and underestimation of the seriousness of this health condition could contribute to poor compliance with CPAP treatment protocol among patients diagnosed with OSA. Our review will fill the gap of how newly Thai OSA patients adhere to CPAP treatment and their perception of the health benefits of the treatment. This information can confirm the effectiveness of CPAP, especially on daytime functioning which is the outcome that was not consistently reported in the previous studies.

With the postulation that subjective sleep quality, daytime sleepiness and daytime functioning might be improved and recognized by the patient sooner than the benefit to the metabolic, cardiovascular and premature mortality outcomes. We conducted a repeated measure study with the primary objective of assessing the effects of CPAP utilization on sleep quality, daytime sleepiness and daytime functioning among a group of patients newly diagnosed with OSA and who were prescribed to undergo CPAP treatment. The secondary objective is the comparison of the differences in these outcomes between patients who had adhered and those who did not adhere to CPAP utilization. We hypothesized that CPAP treatment improves all these outcomes and the improvement of the outcomes has a linear relationship to adherence to CPAP utilization.

\section{Methods \\ Study design and participants}

The repeated measures clinical intervention design was used (before and at 1-month and 3-months follow-up). This study was implemented at the Sleep Disorder Center, Center for Medical Excellence Faculty of Medicine Chiang Mai University, Thailand. A total of 50 patients who were diagnosed for the first time with OSA were recruited to participate in the study by research assistants. The sample size was calculated using $\mathrm{G}^{*}$ Power based on the 
JHR

36,5

974

statistical power of $95 \%, \alpha=0.05$, and using means-difference between two dependent means (matched pairs) based on the previous study of Lau et al. [9]. The effect size for each outcome ranged from $0.6-0.71$ which the calculation of sample size was ranging from 28-39 participants. We estimated the attrition rate to be about $20 \%$; therefore, we increased the sample size to 50 participants.

Patients were eligible to participate in this study if (1) they had been diagnosed with moderate to severe OSA (apnea-hypopnea index [AHI] $\geq 15$ events/hours) by polysomnography (PSG) and accepted CPAP treatment, (2) a minimum age of 18 years, and (3) ability to communicate in the Thai language. Patients were excluded if they had been diagnosed with serious mental health and/or if they were taking prescriptions for psychiatric disorders.

\section{Interventions}

The research assistance approached the participants who met the inclusion criteria. The participants who accepted to use the CPAP device visited the sleep outpatients clinic. The interventions are composed of trying out of CPAP machine and types of mask, education, follow-up and feedback on CPAP use to enhance CPAP adherence and decrease side effects from using CPAP devices.

(1) The sleep physician prescribed mode and CPAP pressure for each patient based on the polysomnography information and CPAP titration results. Participants tried out the CPAP devices about one week before deciding on which types of mask they felt comfortable with.

(2) All patients received CPAP education from the sleep physician and nursing staff at the sleep clinic once they consented to CPAP treatment. The education related to the impact of OSA, health behaviors change (e.g. weight loss and sleep hygiene), how to use CPAP machine, the benefits of CPAP, side effects and how to deal with the side effects were provided verbally and written information.

(3) Follow-up appointments were scheduled at 1- month and 3-months post their use of CPAP machines. During each follow-up visit, the participants have to bring the SD card of the CPAP device to download information relating to hours use and day use and record in the CPAP use recording form. This information was analyzed by the sleep physician to measure CPAP adherence. The information was feedback and discuss with the participants on their adherence and then encouraging them to continue using CPAP device regularly. The ESS and FOSQ were measured to follow up on the effectiveness of the treatment as well as other clinical information. Moreover, patients were asked to report technical problems and side effects they had encountered while using their CPAP devices. The physician in charge resolved these problems by providing suggestions about overcoming some of the encountered problems. If necessary, medications were prescribed to alleviate the unpleasant side effects of CPAP utilization.

\section{Measurements}

Data on sociodemographic and lifestyle factors were collected at the baseline, using a selfadministered questionnaire. Outcome parameters were collected at the baseline, 1-month, and at 3-months of the study. Information on CPAP utilization was downloaded from the Smartcard (SD cards) recorded by prescribed CPAP devices during each follow-up visit at 1 and 3 months. The measurements used in this study included 4 self-report questionnaires and data downloaded from the SD card of the CPAP devices. 
The first instrument is a clinico-demographic questionnaire; variables e.g. sociodemographic variables, lifestyle behaviors, co-existing health conditions, body mass index (BMI), Apnea/Hypopnea Index (AHI), mode of CPAP use, and CPAP pressure were collected.

Second, the Thai version of the Pittsburgh Sleep Quality Index (Thai-PSQI) was used to measure sleep quality over the previous month [13]. It comprises 19 self-rated items categorized into seven components: sleep latency, sleep duration, sleep disturbances, habitual sleep efficiency, subjective sleep quality, use of sleep medications and daytime dysfunction. Summing the seven component scores yields one global sleep score ranging from 0 to 21 and a score of 5 or more indicates as having low sleep quality $[13,14]$. The global scores of the ThaiPSQI were found to show good internal consistency with a Cronbach's alpha of 0.84 and testretest reliability of 0.89 [13]. The internal consistency of this instrument in our study was 0.73 .

Third, the Thai version of the Epworth Sleepiness Scale (Thai-ESS) [15] was used to assess the level of daytime sleepiness. Respondents were asked to report how likely they were to doze off or fall asleep during the day in various situations. Responses are recorded on a fourpoint Likert scale ranging from 0 (would never doze) to 3 (high chance of dozing). Total scores ranged from 0 to 24 , and scores $\geq 10$ indicate excessive daytime sleepiness. The Thai version of the ESS was developed using back- translation, and the instrument's quality was validated. The Thai-ESS's internal consistency was reported as 0.87 indicating acceptable reliability [15]. The reliability of the Thai ESS in our study was 0.81 .

Fourth, the short version of the Functional Outcomes of Sleep Questionnaire (FOSQ-10) was translated into Thai using a back translation process by bilingual translators. Following back translation the instrument was sent to the original developer who affirmed that the two versions were identical in meaning. The short version comprises 10 items and is divided into 5 subscales and includes general productivity, activity level, vigilance, social outcomes and intimacy and sexual relationships. The scale ranged from "no difficulty" to "extreme difficulty." Each subscale was computed for mean-weight item score and subscale scores totaled to yield a global score. The higher the score the better the daytime functioning. The reliability of the instrument was reported in terms of internal consistency as 0.87 [16] which was the same value in our study. Permissions were obtained from the authors for the use of and translation of instruments.

For each study participant, information about the total number of nights of CPAP utilization, the number of nights that CPAP was not utilized, and a total hour per night of CPAP utilization were downloaded from the SD card. Additionally, data expressed as a percentage, on full nights of CPAP utilization; nights with CPAP utilization $\geq 4 \mathrm{~h} /$ night; and CPAP utilization $<4 \mathrm{~h} /$ night were collected. In our study, CPAP adherence was defined as CPAP utilization $\geq 4 \mathrm{~h} /$ night and utilization of at least $70 \%$ of the total night.

\section{Ethical considerations}

All procedures performed in studies involving human participants were in accordance with the ethical standards of the Research Ethical Committee of the Faculty of Medicine, Chiang Mai University, Thailand (study code number MED-2558-03591, approval no. 301/2559).

\section{Data analysis}

The demographic characteristics of the subjects were assessed using descriptive statistics. We defined outcomes as changes in scores for PSQI, ESS and FOSQ-10. Scores were assessed at baseline, 1-month, and 3-months follow-up. Test of normality using Shapiro-Wilk test revealed that data was a normal distribution.

Nonparametric statistical analysis tests for trend were applied to test the differences of each outcome at baseline, 1-month, and 3-months follow-up. 
JHR

36,5

976

We used a repeated measure statistical approach by applying the multilevel mixed-effects modeling technique to assess the effectiveness of CPAP treatment on sleep quality, daytime sleepiness and daytime functioning of patients with OSA at 1-month and 3-month follow period after controlling for adherence to CPAP use and demographic characteristics with a multi-level mixed. All statistical analyses were two-sided. The level of statistical significance was assumed at a $p$-value of 0.05 or lower. The statistical analyses were performed using a statistical package.

\section{Results}

Demographic characteristics

Fifty patients were enrolled in the study; however, only 39 patients completed the 3 months' intervention follow-up time. One patient was excluded at one month and 11 patients were excluded at 3-months because of missing the timeline for clinical evaluation (Figure 1). Patients' baseline characteristics are shown in Table 1 . Of the 39 participants, $66 \%(n=33)$ were male with a mean age of 53.2 years (range $23-74$ years). About $84 \%(n=42)$ of patients reported at least one comorbid health condition and $74 \%(n=37)$ met the clinical definition of overweight $(\mathrm{BMI} \geq 25)$. At baseline, $90 \%(n=45)$ of patients had a severe AHI level. Patients were given prescribed fixed pressure CPAP, which ranged from 6-18 $\mathrm{cm} \mathrm{H}_{2} \mathrm{O}$. At the 1-month benchmark, $53.2 \%(n=25)$ of patients had met the definition of CPAP adherence. This proportion increased to $71.1 \%(n=27)$ by the 3 -months benchmark.
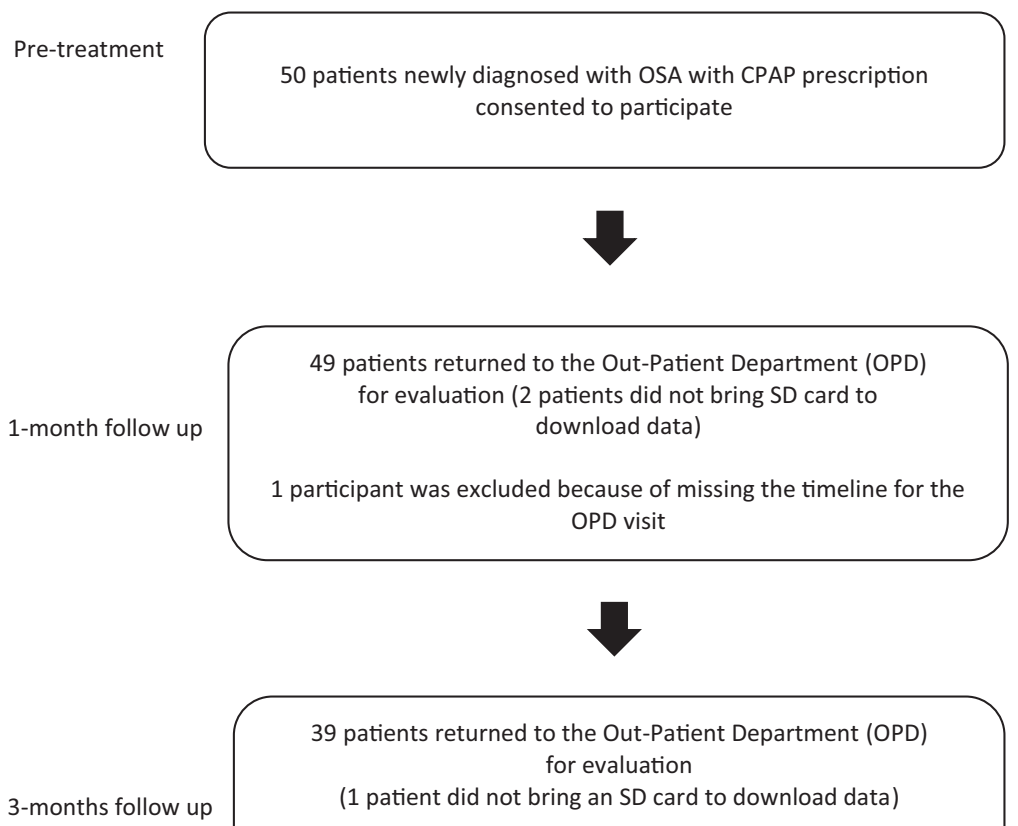

Figure 1.

Study flow

10 additional participants were excluded because of missing the timeline for the OPD visit 


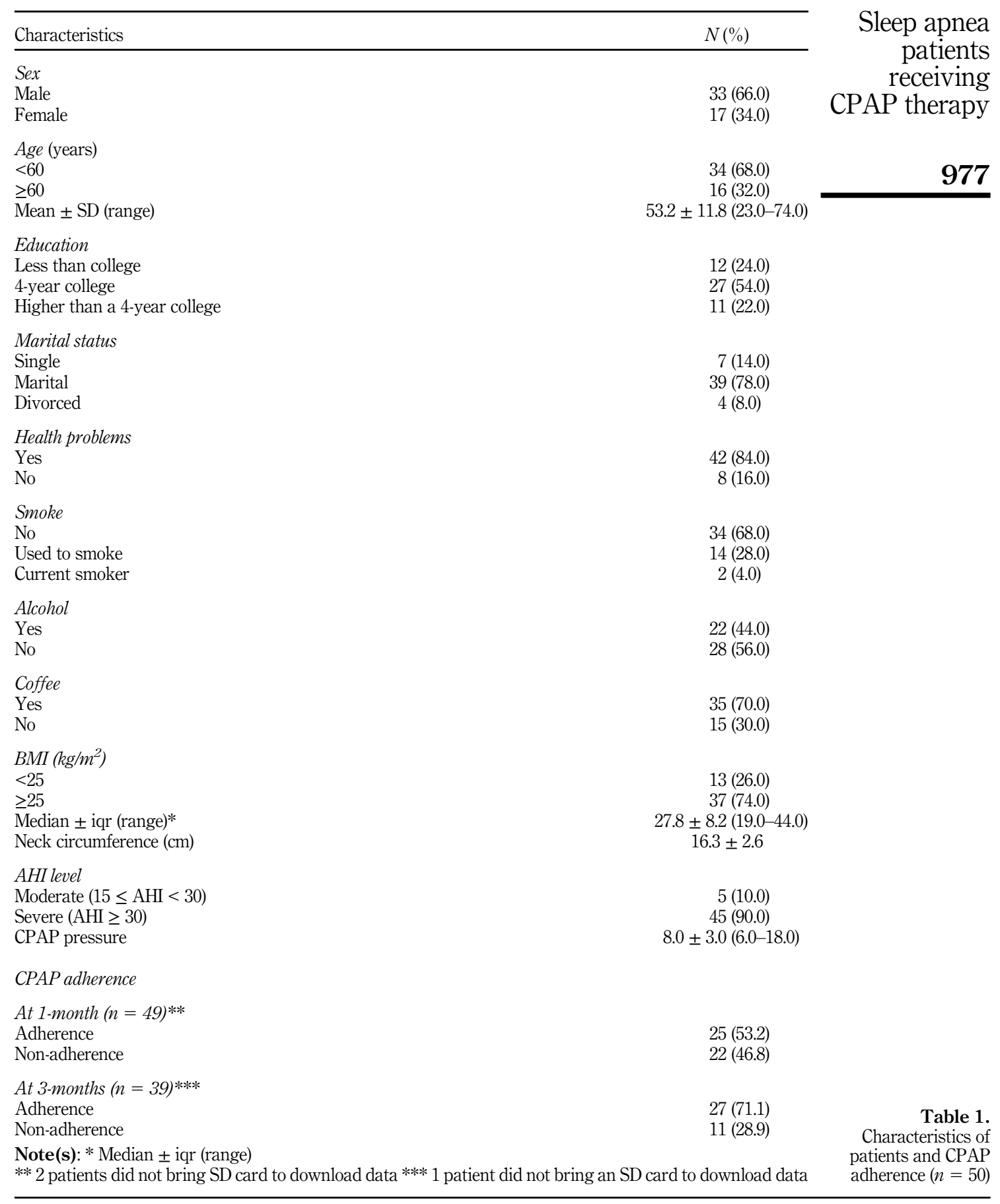


JHR

36,5

\section{8}

Table 2.

Comparison of sleep quality, daytime sleepiness and daytime functioning of patients with OSA at baseline and after CPAP treatment at 1-month and 3-month periods
The effects of CPAP utilization on sleep quality, daytime sleepiness and daytime functioning Sleep quality. At the baseline, $46 \%(n=23)$ of participants were categorized as having good sleep quality (PSQI score $<5$ ). The proportion of patients with good quality of sleep slightly dropped to $44.9 \%(n=22)$ after 1 month of CPAP utilization; however, by the end of the follow-up time, the number of patients with good quality of sleep increased to $71.8 \%(n=28)$ but not reach the statistical significance (trend $p=0.27$ ).

Daytime sleepiness. At the baseline, $52 \%(n=26)$ of the participants reported of excessive daytime sleepiness; this proportion significantly dropped to $20.4 \%(n=10)$ after 1 month of CPAP utilization and $15.4 \%(n=6)$ after 3 months (trend $p<0.001$ ).

Daytime functioning. The mean score of FOSQ at baseline was 13.1 and significantly increased to 16.9 at 1 month and 18.6 at the end of the study (trend $p<0.001$ ), Table 2.

\section{Comparison of treatment outcomes between participants in adherence and non-adherence groups}

We compared each outcome between participants in the adherence and nonadherence group at 1-month and 3-months. The results showed that at 1-month follow-up, there were no statistically significant differences of all outcomes between the two groups. However, at 3 -months follow-up, participants in the adherence group had better sleep quality scores $(p<0.01)$ whereas daytime sleepiness and daytime functioning were not different between the two groups (Table 3).

We evaluated the potential impact of compliance with CPAP treatment on daytime sleepiness and daytime functioning by using the multilevel mixed-effects modeling technique. We detected a statistically significant reduction in daytime sleepiness and improvement of daytime functioning, independent of CPAP adherence at one month and three months of the trial $(p<0.001)$. Having comorbidities was related to sleep quality; therefore, we controlled for comorbidities and adherence with CPAP treatment using multilevel mixed-effects modeling statistical technique. The results revealed significant improvement of sleep quality at 1-month follow-up, the intervention improved quality of sleep $(\beta=-2.65,95 \% \mathrm{CI}=-1.60,-4.13)$, daytime functioning $(\beta=3.24,95 \% \mathrm{CI}=1.87,4.61)$ and decreased daytime sleepiness $(\beta=-3.29,95 \% \mathrm{CI}=-1.85,-4.73)$. At 3 months, the intervention still improved quality of sleep $(\beta=-3.53,95 \% \mathrm{CI}=-2.05,-5.01)$, and daytime functioning $(\beta=4.34,95 \% \mathrm{CI}=2.76,5.92)$, and decreased daytime sleepiness $(\beta=-4.82$, $95 \% \mathrm{CI}=-3.16,-6.49)$, Table 4.

\begin{tabular}{|c|c|c|c|c|}
\hline Characteristics & $\begin{array}{l}\text { Baseline } \\
(n=50)\end{array}$ & $\begin{array}{c}1 \text { month after treatment } \\
(n=49)\end{array}$ & $\begin{array}{c}3 \text { months after treatment } \\
(n=39)\end{array}$ & $\begin{array}{l}\text { Global } \\
p \text {-value* }\end{array}$ \\
\hline \multicolumn{5}{|l|}{ PSQI score } \\
\hline Good & $23(46.0)$ & $22(44.9)$ & $28(71.8)$ & 0.027 \\
\hline Poor & $27(54.0)$ & $27(55.1)$ & $11(28.2)$ & \\
\hline Mean \pm SD & $10.1 \pm 4.1$ & $6.2 \pm 3.1$ & $4.8 \pm 2.7$ & $<0.001$ \\
\hline \multicolumn{5}{|l|}{ ESS score } \\
\hline Normal & $24(48.0)$ & $39(79.6)$ & $33(84.6)$ & $<0.001$ \\
\hline Abnormal & $26(52.0)$ & $10(20.4)$ & $6(15.4)$ & \\
\hline Mean \pm SD & $10.5 \pm 4.8$ & $7.3 \pm 3.8$ & $5.4 \pm 3.5$ & $<0.001$ \\
\hline \multicolumn{5}{|l|}{ FOSQ score } \\
\hline \multicolumn{5}{|c|}{$\begin{array}{l}\text { Note(s): PSQI = Pittsburgh Sleep Quality Index, ESS = Epworth Sleepiness Score, FOSQ = Functiona } \\
\text { Outcomes of Sleep } \\
*_{p \text {-value from nonparametric tests for trend }}\end{array}$} \\
\hline
\end{tabular}




\begin{tabular}{|c|c|c|c|c|c|c|c|}
\hline \multirow[b]{2}{*}{ Characteristics } & \multicolumn{2}{|c|}{1 month } & \multicolumn{4}{|c|}{3 months } & \multirow{4}{*}{$\begin{array}{l}\text { Sleep apnea } \\
\text { patients } \\
\text { receiving } \\
\text { CPAP therany }\end{array}$} \\
\hline & Adherence & Non-adherence & $p$-value & Adherence & Non-adherence & $p$-value & \\
\hline PSQI score & & & & & & & \\
\hline Good & $13(52.0)$ & $9(40.91)$ & $0.447^{*}$ & $22(84.62)$ & $4(36.36)$ & $0.003 *$ & \\
\hline Poor & $12(48.0)$ & $13(59.09)$ & & $\begin{array}{c}4(15.38) \\
(n=26)\end{array}$ & $7(63.64)$ & & \\
\hline Mean \pm SD & $5.60 \pm 2.51$ & $\begin{array}{c}6.81 \pm 3.60 \\
(n=21)\end{array}$ & $0.188^{* *}$ & $\begin{array}{c}3.82 \pm 1.92 \\
(n=22)\end{array}$ & $\begin{array}{c}6.80 \pm 3.22 \\
(n=10)\end{array}$ & $0.018^{* *}$ & 979 \\
\hline \multicolumn{8}{|l|}{ ESS score } \\
\hline Normal & $18(72.0)$ & $19(86.36)$ & $0.230^{*}$ & $24(88.89)$ & 8 (72.73) & $0.215^{*}$ & \\
\hline Abnormal & $7(28.0)$ & 3 (13.64) & & 3 (11.11) & $3(27.27)$ & & \\
\hline Mean \pm SD & $7.52 \pm 4.20$ & $6.95 \pm 3.59$ & $0.625^{* *}$ & $5.11 \pm 3.38$ & $6.63 \pm 3.59$ & $0.223^{* *}$ & Table 3. \\
\hline $\begin{array}{l}\text { FOSQ score } \\
\text { Mean } \pm \text { SD }\end{array}$ & $17.73 \pm 2.70$ & $16.32 \pm 2.79$ & $0.086^{* *}$ & $18.87 \pm 2.25$ & $17.79 \pm 2.99$ & $0.233^{* *}$ & $\begin{array}{l}\text { Comparison of } \\
\text { outcomes at 1-month } \\
\text { and 3-month follow }\end{array}$ \\
\hline \multicolumn{7}{|c|}{$\begin{array}{l}\text { Note(s): PSQI = Pittsburgh Sleep Quality Index, ESS = Epworth Sleepiness Score, FOSQ = Functional } \\
\text { Outcomes of Sleep } \\
* \text { Pearson chi-square, **t-test }\end{array}$} & $\begin{array}{l}\text { period between } \\
\text { adherence group and } \\
\text { non-adherence group }\end{array}$ \\
\hline
\end{tabular}

\begin{tabular}{|c|c|c|c|c|}
\hline After treatment* & Coefficient & $95 \% \mathrm{CI}$ & $p$-value & \multirow[b]{2}{*}{ Table 4.} \\
\hline \multicolumn{4}{|l|}{ PSQI score } & \\
\hline 1-month period & -2.65 & $-1.60--4.13$ & $<0.001$ & Effectiveness of CPAP \\
\hline 3-month period & -3.53 & $-2.05--5.01$ & $<0.001$ & treatment on sleep \\
\hline \multicolumn{4}{|l|}{ ESS score } & $\begin{array}{l}\text { quality, daytime } \\
\text { sleepiness and daytime }\end{array}$ \\
\hline 1-month period & -3.29 & $-1.85--4.73$ & $<0.001$ & functioning of patients \\
\hline 3-month period & -4.82 & $-3.16--6.49$ & $<0.001$ & with OSA at 1-month \\
\hline \multicolumn{4}{|l|}{ FOSQ score } & and 3-month follow \\
\hline 1-month period & 3.24 & $1.87-4.61$ & $<0.001$ & period after controlling \\
\hline 3-month period & 4.34 & $2.76-5.92$ & $<0.001$ & use and demographic \\
\hline \multicolumn{4}{|c|}{$\begin{array}{l}\text { Note(s): PSQI = Pittsburgh Sleep Quality Index, ESS = Epworth Sleepiness Score, FOSQ= Functional } \\
\text { Outcomes of Sleep } \\
\text { *compared with pre-treatment }\end{array}$} & $\begin{array}{r}\text { characteristics with a } \\
\text { multi-level } \\
\text { mixed model }\end{array}$ \\
\hline
\end{tabular}

\section{Discussion}

Our study is the first to report on the effectiveness of CPAP on subjective outcomes for short and long-term use of CPAP among Thai patients with OSA. We found that after a short period of CPAP use as 1 month, sleep quality and daytime functioning improved, while daytime sleepiness decreased. Importantly, at 3 months after CPAP utilization, improvement of all outcomes was shown. Our findings concur with previous studies in other countries reporting CPAP utilization improves the quality of sleep and daytime functioning $[9,10]$.

The improvement of perceived sleep quality among our participants was the result of the effects of CPAP treatment. Generally, CPAP improved nighttime oxygenation, reduced sleep fragmentation and increase the proportion of deep sleep stages in a patient with OSA [11]. Moreover, it increases the number of sleep spindles which play an important role in sleep quality [17]. Interestingly, at a 1-month follow-up, the number of participants who were classified as good sleepers did not increase despite a decrease in the mean PSQI scores of the group. The discrepancy between the two follow-up periods might be attributed to the time 
JHR

36,5

980 needed by the participant to acclimatization with their device use and the lack of awareness about the magnitude of improvement in their sleep quality.

Findings from our study are consistent with a previous study of moderate to severe OSA patients which daytime sleepiness and daytime functioning showed improvement in the adherent group [18]. Daytime sleepiness is a predominant symptom of OSA. It is also the main reason for patients with OSA seek medical treatment. Patients with moderate to severe OSA who received CPAP treatment had improvements in ESS scores after 2 and 6 months of treatment indicating the effectiveness of CPAP treatment over the long term [19]. In our study, we detected that the proportion of participants with a normal level of sleepiness substantially increased after 1 month and at 3 months of CPAP utilization. Weaver and colleagues [20] have suggested a linear dose-response relationship between the number of hours of CPAP utilization and daytime sleepiness. Regular CPAP utilization can be important in the reduction of daytime sleepiness; improvement of daytime functioning reaches a plateau after 7 hours of CPAP utilization. The 7-h threshold effect of CPAP utilization on daytime functioning potentially is an indication of the influence of other variables on daytime functioning.

We considered the first month after CPAP utilization as a crucial point to address participants' concerns and problems associated with their CPAP devices. Also, the outcome in terms of subjective sleep quality, daytime sleepiness and daytime functioning might be improved and recognized sooner than the benefit to metabolic, cardiovascular and premature mortality. This vulnerable period would be a great opportunity for impression generation and long-term compliance enhancement. Additionally, the specific CPAP education which targets individuals at risk for low compliance was the other helpful strategy to explain the improvement in the CPAP adherence among the participants in our study. However, adherence to CPAP treatment is complicated and many factors influence its regular utilization. Factors related to $\mathrm{CPAP}$ adherence include demographic characteristics, disease characteristics, side effects of CPAP utilization, and psychosocial factors of an individual patient [21]. These factors should be explored more among Thai OSA patients.

Our study has its strengths and limitations. The main strengths of our study are the use of standardized and validated instruments for data collection and the implementation of objective measures to assess CPAP adherence. The self-report questionnaires in our study were also accepted and widely used in sleep research for measuring outcomes of CPAP treatment.

Our study has one major limitation. The relatively small sample size of our study most likely restricts its generalizability. The participants were not follow up at the time assigned. Some of them were followed up after the time assigned which we cannot determine the CPAP adherence at 1 and 3 months follow-up time exactly. Additionally, we did not incorporate a control group in this study. However, we aimed to identify the effectiveness of CPAP treatment in routine clinical practice; therefore, implementation of a study with a control arm would have required deprivation of patients from CPAP treatment. This approach most likely would have been unethical.

In our study, improvement of outcomes depending on how to adhere to the CPAP treatment. Adherence to CPAP use proves its effectiveness on a subjective perception of sleep quality and daytime function. Therefore, the intervention to promote CPAP adherence is needed to be implemented. Regular use of CPAP can be enhanced by providing education related to the impact of OSA and benefits of CPAP treatment as well as management of barriers to use CPAP.

\section{Conclusion}

CPAP is an effective treatment for patients with moderate to severe OSA. Its effectiveness depends on treatment adherence. Improved outcomes can be achieved with short and longterm use; however, with a longer duration of utilization, better outcomes should be expected. 
Our results suggest that $\mathrm{CPAP}$ adherence at 1-month follow-up was quite low compared to at 3-months. Multiple factors could have contributed to the low adherence during the first month of utilization which we would like to label as the "Adjustment Period." It is important to discern the barriers to proper utilization and adherence to CPAP during this period; the effectiveness of CPAP adherence depends on compliance with the treatment protocol.

For patients, CPAP treatment is effective to improve health outcomes which CPAP adherence is a major factor for the improvement. The more adherence they have, the more benefits they gain. Patient-centered interventions should be developed to facilitate a transition to CPAP utilization and continuous adherence to treatment protocols. The intervention should be combined with many components such as education, feedback on CPAP use, and regular follow-up. Our result is a benefit for public health that it will raise a concern about how important CPAP treatment and adherence to CPAP among OSA patients. For future research, objective parameters such as cardiovascular and neurobehavioral variables should be evaluated. Moreover, long-term follow-up and monitoring systems for CPAP adherence should be implemented.

Conflicts of Interest: None

\section{References}

1. Rotenberg BW, Murariu D, Pang KP. Trends in CPAP adherence over twenty years of data collection: a flattened curve. J Otolaryngol Head Neck Surg. 2016; 45(1): 43. doi: 10.1186/s40463016-0156-0.

2. Peppard PE, Young T, Barnet JH, Palta M, Hagen EW, Hla KM. Increased prevalence of sleepdisordered breathing in adults. Am J Epidemiol. 2013; 177(9): 1006-14. doi: 10.1093/aje/kws342.

3. Mirrakhimov AE, Sooronbaev T, Mirrakhimov EM. Prevalence of obstructive sleep apnea in Asian adults: a systematic review of the literature. BMC Pulm Med. 2013; 13: 10. doi: 10.1186/ 1471-2466-13-10.

4. Neruntarat C, Chantapant S. Prevalence of sleep apnea in HRH princess Maha Chakri Srinthorn medical center, Thailand. Sleep \& breathing = Schlaf \& Atmung. 2011; 15(4): 641-8. doi: 10.1007/ s11325-010-0412-x.

5. Jacobsen JH, Shi L, Mokhlesi B. Factors associated with excessive daytime sleepiness in patients with severe obstructive sleep apnea. Sleep Breath. 2013; 17(2): 629-35. doi: 10.1007/s11325-0120733-z.

6. Ozer C, Etcibasi S, Ozturk L. Daytime sleepiness and sleep habits as risk factors of traffic accidents in a group of Turkish public transport drivers. Int J Clin Exp Med. 2014; 7(1): 268-73.

7. Levy P, Tamisier R, Minville C, Launois S, Pepin JL. Sleep apnoea syndrome in 2011: current concepts and future directions. Eur Respir Rev. 2011; 20(121): 134-46. doi: 10.1183/09059180.00003111.

8. Usmani ZA, Chai-Coetzer CL, Antic NA, McEvoy RD. Obstructive sleep apnoea in adults. Postgrad Med J. 2013; 89(1049): 148-56. doi: 10.1136/postgradmedj-2012-131340.

9. Lau EY, Eskes GA, Morrison DL, Rajda M, Spurr KF. The role of daytime sleepiness in psychosocial outcomes after treatment for obstructive sleep apnea. Sleep Disord. 2013; 2013: 140725. doi: 10.1155/2013/140725.

10. Bjornsdottir E, Janson C, Sigurdsson JF, Gehrman P, Perlis M, Juliusson S, et al. Symptoms of insomnia among patients with obstructive sleep apnea before and after two years of positive airway pressure treatment. Sleep. 2013; 36(12): 1901-9. doi: 10.5665/sleep.3226.

11. Neikrug AB, Liu L, Avanzino JA, Maglione JE, Natarajan L, Bradley L, et al. Continuous positive airway pressure improves sleep and daytime sleepiness in patients with Parkinson's disease and sleep apnea. Sleep. 2014; 37(1): 177-85. doi: 10.5665/sleep.3332.

12. Sawunyavisuth B. What personal experiences of CPAP use affect $\mathrm{CPAP}$ adherence and duration of CPAP use in OSA patients?. J Med Assoc Thai. 2018; 101: s245-s9. 
JHR 36,5

982
13. Sitasuwan T, Bussaratid S, Ruttanaumpawan P, Chotinaiwattarakul W. Reliability and validity of the Thai version of the Pittsburgh sleep quality index. J Med Assoc Thailand $=$ Chot Thangphaet. 2014; 97(Suppl 3): S57-67.

14. Buysse DJ, Reynolds CF 3rd, Monk TH, Berman SR, Kupfer DJ. The Pittsburgh Sleep Quality Index: a new instrument for psychiatric practice and research. Psych Res. 1989; 28(2): 193-213. doi: 10.1016/0165-1781(89)90047-4.

15. Banhiran W, Assanasen P, Nopmaneejumruslers C, Metheetrairut C. Epworth sleepiness scale in obstructive sleep-disordered breathing: the reliability and validity of the Thai version. Sleep \& breathing = Schlaf \& Atmung. 2011; 15(3): 571-7. doi: 10.1007/s11325-010-0405-9.

16. Chasens ER, Ratcliffe SJ, Weaver TE. Development of the FOSQ-10: a short version of the functional outcomes of sleep questionnaire. Sleep. 2009; 32(7): 915-9. doi: 10.1093/sleep/32.7.915.

17. Yetkin O, Aydogan D. Effect of CPAP on sleep spindles in patients with OSA. Respir Phy Neur. 2018; 247: 71-3. doi: 10.1016/j.resp.2017.09.008.

18. Antic NA, Catcheside P, Buchan C, Hensley M, Naughton MT, Rowland S, et al. The effect of CPAP in normalizing daytime sleepiness, quality of life, and neurocognitive function in patients with moderate to severe OSA. Sleep. 2011; 34(1): 111-9. doi: 10.1093/sleep/34.1.111.

19. Batool-Anwar S, Goodwin JL, Kushida CA, Walsh JA, Simon RD, Nichols DA, et al. Impact of continuous positive airway pressure (CPAP) on quality of life in patients with obstructive sleep apnea (OSA). J Sleep Res. 2016; 25(6): 731-8. doi: 10.1111/jsr.12430.

20. Weaver TE, Maislin G, Dinges DF, Bloxham T, George CF, Greenberg H, et al. Relationship between hours of CPAP use and achieving normal levels of sleepiness and daily functioning. Sleep. 2007; 30(6): 711-9. doi: 10.1093/sleep/30.6.711.

21. Weaver TE, Sawyer AM. Adherence to continuous positive airway pressure treatment for obstructive sleep apnoea: implications for future interventions. Indian J Med Res. 2010; 131: 245-58.

\section{Corresponding author}

Jindarat Chaiard can be contacted at: jindarat.c@cmu.ac.th

For instructions on how to order reprints of this article, please visit our website:

www.emeraldgrouppublishing.com/licensing/reprints.htm

Or contact us for further details: permissions@emeraldinsight.com 